\title{
Examining transport futures with scenario analysis and MCA.
}

Dr Robin Hickman, Bartlett School of Planning, University College London. r.hickman@ucl.ac.uk

Sharad Saxena, Environmental Change Institute, University of Oxford and Asian Development Bank.

David Banister, Transport Studies Unit, School of Geography and the Environment, University of Oxford.

Olu Ashiru, Director, Takedo International.

\begin{abstract}
Climate change is a global problem and across the world the transport sector is finding it difficult to break projected increases in carbon dioxide $\left(\mathrm{CO}_{2}\right)$ emissions; there are very few contexts where deep reductions in transport $\mathrm{CO}_{2}$ emissions are being made. A number of research studies are now examining the potential for future lower $\mathrm{CO}_{2}$ emissions in the transport sector. This paper develops this work to consider some of the wider sustainability impacts (economic, social and local environmental) as well as the lower $\mathrm{CO}_{2}$ transport impacts of different policy trajectories. Hence the central argument made is for an integrated approach to transport policy making over the longer term - incorporating scenario analysis and multi-criteria assessment (MCA) - to help assess likely progress against a range of objectives.
\end{abstract}

The analysis is based on work carried out in Oxfordshire, UK. Different packages of measures are selected and two scenarios developed which satisfy lower $\mathrm{CO}_{2}$ aspirations, one of which also provides wider positive sustainability impacts. A simulation model has been produced to help explore the strategic policy choices and tensions evident for decisionmakers involved in local transport planning. The paper argues for a 'strategic conversation' (Van der Heijden, 1996) at the sub-regional and city level, based upon future scenario analysis and MCA, discussing the priorities for intervention. Such an approach will help us examine the scale of change and trade-offs required in moving towards sustainable transport futures.

\section{Keywords}

Climate change

Low carbon

Transport

Multi criteria appraisal

Futures

Oxfordshire 


\section{Introduction}

The transition to sustainable transport futures demands an integrated approach to transport policy development and implementation. This includes lowering carbon dioxide $\left(\mathrm{CO}_{2}\right)$ emissions in transport, and achieving progress against wider economic, social and local environmental policy objectives. Boarnet (2010) notes the imperative for action internationally, that externalities from greenhouse gas emissions will and should be one of the most important considerations in transportation policy in the decades ahead. The global perspective is taken by Schäfer and Victor (2000) and Schäfer et al. (2009), estimating that the 'average world citizen' in 2050 may travel as many kilometres as the average European in 1990, with the world citizen's travel distance increasing from an aggregate 38,000 billion passenger km (2005) to between 104,000-150,000 billion passenger km in 2050. Alongside, Sperling and Gordon (2009) predict two billion cars globally by 2030. Against this projected increase in travel and motorisation, achieving a reduction in transport $\mathrm{CO}_{2}$ emissions will be very difficult, even with significant improvements in vehicle technologies. A major problem is that any gains from improved vehicle efficiencies tend to be offset by increases in travel distance; hence there is a major behavioural dimension that is usually overlooked.

There are also issues of appropriate scale for policy-making. The recent problems in finding a consensus on climate change at the international level (cf. the recent Conferences of the Parties at Copenhagen, 2009; Cancún, 2010; and Durban, 2011) may mean that the onus for action has moved to city, regional and national governments. The greatest progress appears to be being made at the city and regional levels, but there are still major difficulties in implementing strategies of sufficient innovation to contribute in any meaningful way to national sustainability and $\mathrm{CO}_{2}$ reduction targets.

An increasing number of authors have examined the interventions and potential mitigation pathways available to reduce emissions in the transport sector. Developing from very early thoughts on strategic responses (such as Hughes, 1993; Schipper and Meyers, 1993; Greene, 1993; RCEP, 1994), the literature in this area has gradually developed. More recently analysis has reviewed the policy measures and mechanisms available and developed scenario analysis and implementation pathways to reduce transport emissions (for example, the EU-POSSUM project, 1998; Banister et al., 2000; Schipper et al., 2000; OECD, 2000; Shiftan et al., 2003; Pridmore et al., 2003; Geurs and Van Wee, 2004; Åkerman and Höjer, 2006; Hickman and Banister, 2007; Anable and Bristow, 2007; Niemier et al., 2008; Bristow et al., 2008; Hickman et al., 2009; Yang et al., 2009; Schäfer et al., 2009; Cambridge Systematics, 2009; Hickman et al., 2010; Stanley et al., 2011; Brand et al., in press; and many more).

Related research focuses on the contribution of particular policy areas to sustainable travel; such as urban structure and travel, including the relationship with attitudes (such as Breheny, 1997; Cervero and Kockelman, 1997; Newman and Kenworthy, 1999; Ewing and Cervero, 2001; Handy et al., 2005; Schwanen and Mokhtarian, 2005; Levinson and Krizek, 2008; Ewing et al., 2008; Cao et al., 2009; Bohte et al., 2009; Ewing and Cervero, 2010; Hickman, 2010), mobility management (Cairns et al., 2004; Litman, 2010) and freight (McKinnon, 2005; McKinnon, 2007). The strong emerging consensus is that wide-ranging strategies, including 
vehicle technologies and fuels, multi-modal network investments, traffic demand management measures, mobility management initiatives ('smarter choices'), slower speeds and ecological driving, and freight planning will all be required to achieve significant transport $\mathrm{CO}_{2}$ reductions. Individual policy areas will make only limited, but still important, contributions to strategic targets and the effective packaging of programmes of measures is important (Hickman et al., 2010). Other related work considers transport as part of wider energy reduction futures (such as Pacala and Socolow, 2004; MacKay, 2009). The consensus within the research is that there is a need for radical trend-breaks in terms of moving towards sustainable transport futures. There is, however, still a predominance in thinking at the governmental level of the 'technological silver bullet' (all that is required is cleaner mobility, with similar mobility patterns); and in research concerning the 'logic of provision', whereby the development of facilities for public transport use, walking and cycling, alongside pricing, will result in a shift to sustainable travel behaviours (Schwanen et al., 2011). Moving towards sustainable travel is likely to prove more difficult; and this (as yet intractable) dilemma requires major innovations within policy analysis, formulation, implementation and evaluation.

Scenario analysis is perhaps important here in helping us to begin to 'think the unthinkable', and is increasingly being used in the transport field. There is an extensive literature in terms of the general approach (Lindblom, 1959; Kahn, 1962; Kahn and Wiener, 1967; Wack, 1985; Robinson, 1982, 1990; Dreborg, 1996; Schwartz, 1996; Van der Heijden, 1996; Godot, 2000; Frommelt, 2008). The dominant objectives are to develop more effective strategic decisionmaking in view of uncertain trends, and to understand the potential for achieving breaks against dominant trends. A number of important difficulties become evident when undertaking scenario analysis:

- There is a fundamental problem with 'indeterminancy': developments in technologies, public policy and public awareness may not only affect exogenous policy variables, but may change 'the rules of the whole game', i.e. we do not really know what is likely to develop in future years (Popper, 1957; Dreborg, 1996). The 'low probability and high impact' events are known as the 'Black Swans' (Taleb, 2007).

- Policy-makers often do not move beyond 'satisficing', they seek not the 'maximally beneficial' outcomes, but instead the 'minimally acceptable' outcomes, avoiding the innovative but perceived risky options (Simon, 1955; Frommelt, 2008). This moves strategies away from the 'technically optimum', perhaps reflecting concerns over political and public deliverability. There are many examples here, streetscape design and road pricing for example.

- 'Inattentional blindness' (Simons, 1999) can often occur in strategy development. Here important issues are often missed due to the focus on 'the task in hand' and the lack of a wider perspective to decision-making. Perhaps the current focus on low $\mathrm{CO}_{2}$ transport pathways will be an example of this; with the economic, social, health and local environmental policy objectives given less weight.

Wider methodologies such as multi-criteria appraisal (MCA) have also been well utilised in transport planning, particularly in assessments at the project or programme levels, but little, if any to our knowledge, in terms of future scenarios. MCA is particularly useful where the 
different aspects of sustainable transport need to be examined in terms of likely impacts against a range of criteria. In the UK, for example, WebTAG has been very thoroughly developed and this represents the main appraisal methodology used in the UK (DfT, 2010; Dodgson et al., 2009). There is also an emerging preference for approaches that make greater use of multi-actor participation in the design of appraisal frameworks, including assessment against stakeholders' goals and objectives (Macharis et al., 2010).

This paper draws on these conventional and emerging approaches, developing a hybrid approach including scenario analysis, MCA (drawing on Saxena, 2012) and, to an extent, participatory methods. The main contribution is in developing future transport scenarios, and viewing these against their likely sustainability impacts, including potential $\mathrm{CO}_{2}$ mitigation impacts. An approach is used in the analysis as follows:

- STEP 1: a systematic 'sift' of the available options

- STEP 2: development of policy packages and scenarios

- STEP 3: appraisal against a MCA framework (including environmental, economic, social and safety criteria).

The scenarios and MCA framework are constructed using multi-actor discussion and an integrated transport decision assessment and simulation tool (INTRA-SIM) is developed and used to discuss the various layers of the analysis, in particular to assemble and appraise multiple future potential scenarios. The process thus promotes a participatory involvement through stakeholder discussion; the simulation tool allowing a transparent and speedy discussion of the likely impacts of multiple scenarios. Outputs are also presented in a GIS (Geographical Information Systems) interface, hence a spatial analysis of impacts is possible.

A central argument made within the paper is of the need for a 'strategic conversation' (Van der Heijden, 1996) around the most effective packages and scenarios of policy interventions, together with their likely impacts in a future year. This can assist policy making at the local level, making decision-making more transparent and inclusive, focusing on the achievement of strategic policy goals over the long term. Through such a process, particular policy interventions can be assessed, and 'ruled in' or 'ruled out', in a transparent manner against agreed assessment criteria'. There is clearly a need for greater 'ownership' of future transport travel behaviours. It is, in the end, the public who need to carry out their travel behaviours in a manner that is consistent with strategic policy goals ${ }^{2}$, and the overall desire to make much more efficient use of carbon-based resources.

\footnotetext{
${ }^{1}$ The paper draws on work carried out for Oxfordshire County Council by the authors, with the Halcrow Group and Transport Studies Unit, University of Oxford, in developing an Integrated Transport Decision Assessment and Simulation Tool (INTRASIM). This has been used in the development of the Oxfordshire Local Transport Plan (LTP3; published in 2011) and Regional Oxfordshire Delivering a Sustainable Transport Study (DaSTS; published in 2010).

${ }^{2}$ Ownership is used here in the context of participation (rather than purchasing). We are seeking that there is greater involvement in the process of decision-making, so that individuals or groups can better understand, shape and 'buy into' the product (in this case the policy package and sustainable travel behaviours).
} 


\section{The Case Study: Oxfordshire}

The case study used in the analysis is Oxfordshire, a county in the south of the UK with a population of nearly 650,000 (Oxfordshire County Council, 2010). It comprises the historic University City of Oxford - the "city of dreaming spires" (Arnold, 1866) - with origins stretching back to the $5^{\text {th }}$ Century Saxons. There are also a number of large freestanding towns (such as Banbury, Bicester and Didcot), several smaller towns (such as Chipping Norton, Wallingford and Henley), and rural villages and more remote rural areas (Figure 1).

In terms of reducing $\mathrm{CO}_{2}$ emissions, Oxfordshire provides an example of the difficult decisions that have to be taken at the local level. The UK has been the first country to set international binding carbon targets, together with intervening budgets for five year periods. The Climate Change Act (2008) requires emissions to be reduced by at least $80 \%$ by 2050 (on 1990 levels) and an interim target of at least $34 \%$ by 2020 , and it also limits the amounts of carbon that can be offset by investing in projects overseas (the 'credit limit'). This means that substantial and real reductions will have to take place across all sectors of the UK economy, including transport. There is, however, little understanding of the potential to achieve the national targets at the local level.

\section{INSERT FIGURE 1 HERE}

The city of Oxford itself has a population of 165,000 (OCC, 2007) and is a 'county town' that serves a wider sub-regional hinterland, referred to as 'Central Oxfordshire'. The ring of market towns and dormitory settlements is around 10-15 miles from the city. Settlements on the east and south sides of the county are very accessible to London (Oxford is around 60 minutes and Didcot 45 minutes from London Paddington by rail). Neighbouring major urban areas include Reading, Swindon and Milton Keynes.

The Oxford Green Belt was designated in 1956 and has led to the effective containment of the Oxford urban area. The first County Structure Plan was prepared in the 1970s and reflected the then growth model for London, displacing growth to designated towns beyond the Green Belt, principally Banbury, Bicester, Didcot and Witney. This strategy can be viewed as a forerunner to PPG13 (DETR, 2001), where new residential development was encouraged in established urban areas. Here, facilities are more accessible, there are better prospects for local employment creation and higher levels of public transport use. Sporadic development throughout the county has largely been avoided. The unanticipated problem has been that the level of self containment within the designated growth towns has been low. Although 70 percent of the commuting trips of residents in Oxford are 'short' (less than 5 miles), less than 35 percent of trips from the expanded towns are in the same short distance cohort. The majority of trips are in the 5-25 mile distance band, and most are made by car. Car driver distance per resident worker is 3.9 miles in Oxford relative to 8.5 miles in the expanded towns (Headicar, 2010). This 'many-to-many' origin and destination travel pattern creates difficulties for public transport provision throughout Oxfordshire, with many tangential journeys evident as well as more conventional radial journeys centred on Oxford. These types of movement are difficult to serve by public transport. Sustainable transport initiatives are required in Oxford, and also throughout the outlying towns and villages where solutions 
are more difficult to define. It is here that it is most difficult to reduce car dependency. The packaging of initiatives needs to be wide-ranging, including, for example, a reinvigorated focus on the strategic location of development. Growth in a small number of the main urban centres would assist in moving towards sustainable transport by reducing travel distances. Hence there is a need to differentiate between urban areas in locating new development, beyond the generic aspirations of PPG13 (Hickman et al., 2009b).

\section{Sifting of Potential Interventions and Policy Packages}

A wide range of potential interventions is available for use in the Oxfordshire transport planning context. A systematic 'sifting' of the long list of options has been carried out, using the process in Figure 2, to consider those with most apparent merit. This method has been developed for and used in the Oxfordshire LTP3 ${ }^{3}$ and Oxfordshire Regional DaSTS study ${ }^{4}$. This is an iterative process providing the assessment of individual measures against: (Stage 1) national and local policy objectives, problems and opportunities; and (Stage 2) deliverability and feasibility. Refined packages and scenarios are assessed against (Stage 3) the detailed appraisal framework. Stages 1 and 2 represent the initial sifting; Stage 3 involves a more detailed appraisal. The sifting process allows most appraisal effort to be focused on the 'likely winners' in terms of transport options, and it was carried out with the local transport planning experts in Oxfordshire and also wider decision-makers.

If a particular intervention does not score well against any of the three stages it is either modified or dropped. The assessment is based upon a semantic scoring scale $(+3$ for major benefit to -3 for major cost or negative impact). Objectives have been derived from the DaSTS objectives (DfT, 2008a) and also local LTP objectives if these differ significantly. In Stages 1 and 2 the problems and opportunities are generic to the local area (Oxfordshire). Deliverability and feasibility covers issues such as technical feasibility, environmental or legal 'showstoppers', affordability (capital, revenue, funding), stakeholder acceptability (political, public, operator), value for money, and uncertainty and risk. An initial ranking of options and policy packages is then produced. Without a systematic process of this type, the sifting process can tend to be unstructured, and perhaps follow individual or political belief (and/or aspiration and prejudice), suffer from poor transparency, or at least be inconsistent. The scenarios and MCA examine the range of options that could be used to achieve against multi criteria objectives. The next stage in policy development (not covered in this paper) looks at the costs and benefits and implementation issues.

INSERT FIGURE 2 HERE

(Based on Halcrow Group, 2010)

\footnotetext{
${ }^{3}$ The Local Transport Plan (LTP) is a statutory document prepared in the UK under the Transport Act 2000 by the relevant transport authority (County, Unitary and Metropolitan Authorities depending on area). The LTP is a 5-year strategy for the management, maintenance, development and monitoring of the transport system and is used to bid for funding from the UK Department for Transport.

${ }^{4}$ A series of Delivering a Sustainable Transport Strategy (DaSTS) studies were carried out in 2010 as a response to the UK Department for Transport's national DaSTS report. They aim to provide sustainable transport strategies, including a prioritised list of schemes and initiatives, at the regional level.
} 
Policy packages (PPs) are derived from the options taken forward. Each typically has a level of 'applicability' - business as usual (BAU), 'low', 'medium' and 'high'5. Schemes and initiatives are selected for different levels of application according to deliverability, feasibility and cost. The following PPs are used within the Oxfordshire INTRA-SIM modelling:

- PP1 Rail

- PP2 Bus

- PP3 Walk

- PP4 Cycle

- PP5 Highway Infrastructure

- PP6 Traffic Demand Management

- PP7 Pricing

- PP8 Parking Management

- PP9 Park and Ride

- PP10 Land Use Planning

- PP11 Smarter Choice Behavioural Measures

- PP12 Low Emissions Vehicles

- PP13 Alternative Fuels

- PP14 Slower Speeds and Ecological Driving

- PP15 Freight

- PP16 Long Distance Travel Substitution

The more detailed appraisal (Stage 3) provides analysis against the MCA framework. This made use of the WebTAG (DfT, 2010) and DaSTS-based guidance (DfT, 2009) and was carried out in discussion with local stakeholders, again mainly practitioners from Oxfordshire County Council. The Stage 3 appraisal also considers more specific spatial issues by scheme, policy package and scenario (see later discussion). The latter two levels, by package and scenario, are where measurable and significant impacts are most likely to be seen.

\section{Modelling Approach}

Each level of policy package application is modelled using the Central Oxfordshire Transport Model (COTOM), which includes a Saturn-based transport model and Emme2 public transport model. Other datasets used include the latest vehicle/speed $\mathrm{CO}_{2}$ emission factors (DfT, 2008b), modal $\mathrm{CO}_{2}$ emission factors (Defra, 2009) and spatial planning assumptions from the South East Plan (GOSE, 2009). The following system architecture is used within the modelling:

\footnotetext{
5 'Low', 'medium' and 'high' refers to the level of investment or application of a particular policy area. Tables 2 and 3 give a summary specification for level of applicability of each of the scenarios discussed.
} 
- Data input and underlying modelling assumptions provided by means of a comma separated text file and an $\mathrm{xml}$ file;

- Comma separated text file contents are provided by a detailed spreadsheet-based Transport Carbon Calculator (INTRA-SIM CALC);

- A Flash based active-x graphical user interface - this allows non-specialists to engage in the decision-making process.

For all policy packages and enabling mechanisms the MCA outputs are computed relative to the BAU reference case. A working paper provides more details on the INTRA-SIM modelling methodology and assumptions used (Ashiru et al., 2010).

\section{Developing Scenarios and Participatory MCA}

The process of moving from the shortlist of policy measures, through to policy packages and scenarios is shown in Figure 3. A scenario is defined within this paper as a 'cluster' of policy packages, each at varying levels of application. Hence we seek to develop integrated packages at the scenario level, with impacts assessed against a range of MCA indicators, and with the objective of multiple goal advancement. The multi-criteria appraisal is measured along five indicators that cover $\mathrm{CO} 2$, local environmental factors, accessibility, safety and the economy. The MCA framework is based on WebTAG criteria and sub-criteria, with additional inputs after discussion with local officers in Oxfordshire. A list of the MCA indicators is given in Table 1. The purpose of the approach is to rank the different policy packages that would achieve some or all of the target indicators. The focus is on the feasibility of achieving strategic policy goals, rather than a full evaluation of the costs and benefits.

\section{INSERT FIGURE 3 HERE}

INSERT TABLE 1 HERE

Two scenarios are explored below to examine the potential differences in policy approach and the different likely impacts. Both illustrate potential low carbon transport pathways, but involve different approaches. Initially the scenarios are described and then impacts considered.

\subsection{Scenario 1: Satisficing with Technology}

Scenario 1 relies on the technological options of low emission vehicles and alternative fuels, and a very successful delivery of these to the mass market, so that targets for reductions in transport $\mathrm{CO}_{2}$ emissions and the other four indicators can be achieved (Table 2).

The total $\mathrm{CO} 2$ reduction impact is $-1,057,932 \mathrm{tCO}_{2}$ per annum (a $37.4 \%$ reduction relative to the BAU level in 2030). This represents around $2.47 \mathrm{tCO}_{2}$ per capita in 2030 , relative to a $\mathrm{BAU}$ of $4.10 \mathrm{tCO}_{2}$ per capita. If this level of technological penetration could be delivered the gains would be very high, but the assumptions are very ambitious relative to current progress. An average total vehicle fleet emission level of $95 \mathrm{gCO}_{2} / \mathrm{km}$ means the average 
vehicle in the fleet by 2030 equates to the today's leading hybrid and diesel technologies (for example, the current Toyota Prius emits $89 \mathrm{gCO}_{2} / \mathrm{km}$ ). Similar emission gains are expected with HGVs. The penetration of alternative fuels is also very ambitious in assumption: $15 \%$ alternative fuels (mix of LPG, electric, biofuel) in the car, $25 \%$ in HGVs and $40 \%$ in the bus. This strategy is thus risky in achievability terms; it relies on a small number of policy areas and wider measures need to be considered.

INSERT TABLE 2 HERE

This type of implementation pathway would take a major effort from the motor manufacturers, responding to mandatory emission standards, which in turn would require new EU and UK legislation. Actions are thus not taken at the local Oxfordshire level, but instead nationally, internationally and by the market. Consumer purchasing choice would also need to change markedly, perhaps with subsidy in the early years to encourage mass market purchase of low emission vehicles. Clearly the market, at the moment, does not have the necessary momentum or incentives to achieve this level of change. There is a greater role at the governmental level to 'demark' the boundaries for commercial operation and consumer choice, through setting up 'the rules of the market' within which businesses can operate successfully, but where strategic societal goals are also delivered, in this case through the introduction of a low emission vehicle fleet. The low emission vehicle package by itself achieves a major share of the potential reduction in $\mathrm{CO}_{2}$ emissions, and is central to any carbon reduction strategy.

The sustainability impacts of Scenario 1 on the other four indicators are limited, with the exception of an improvement in carbon monoxide (CO) (-32.8\% relative to BAU in 2030 ), which is largely due to the change in fuel mix and less reliance on petrol cars. There no gains made against accessibility, economic or safety objectives as captured in the multi-criteria appraisal framework. Hence the scenario can be viewed as positive in low $\mathrm{CO}_{2}$ terms but it performs poorly against wider sustainability objectives.

The spatial distribution of $\mathrm{CO}_{2}$ emission also varies across the county (Figure 4). The results illustrate the chosen scenario relative to BAU. The dominant impact of lower emissions from vehicles means that the largest relative reductions are seen in the non-urban areas, in the villages and rural areas, where car dependency is highest. Hence this is very much a policy scenario targeted at car users, and the areas where car users are located.

As noted above, this scenario makes some impact on $\mathrm{CO}_{2}$ emissions and $\mathrm{CO}$ reductions (a reduction in transport $\mathrm{CO} 2$ emissions of over $30 \%$ against a national benchmark of at least $50 \%$ by 2030), but it has little impact on the other three sets of indicators. Nevertheless, Scenario 1 can be seen as a starting point in building on technological innovation to increase the range and depth of target achievement through the addition of other policy elements, and this is the focus of Scenario 2.

INSERT FIGURE 4 HERE

\subsection{Scenario 2: Sustainable Mobility}

Scenario 2 uses a much wider range of policy options and it gives a much more balanced approach to reducing $\mathrm{CO}_{2}$ emissions. This means that it also scores more highly against all five criteria (Table 1). The scenario is illustrated in Table 3, together with a summary of the 
interventions considered within each of the policy packages. A wide selection of the policy packages on offer is used, and the total $\mathrm{CO} 2$ reduction impact is $-1,365,697 \mathrm{tCO}_{2}$ per annum (a 48.3\% reduction relative to the BAU level in 2030). This represents around $2.0 \mathrm{tCO}_{2}$ per capita in 2030, relative to a BAU of $4.10 \mathrm{tCO}_{2}$ per capita. A more detailed definition of schemes and initiatives by package is given in Seaborn et al. (2009).

\section{INSERT TABLE 3 HERE}

The major $\mathrm{CO} 2$ reduction impacts arise from the following PPs:

- PP12 Low emission vehicles (high): as in Scenario 1 a high level of application is envisaged. The total car fleet averages $95 \mathrm{gCO} / \mathrm{km}$ and HGVs (fully loaded) 800 $\mathrm{gCO}_{2} / \mathrm{km}$ by 2030 . This level of new vehicle technology penetration will be very difficult to achieve across the whole vehicle fleet. The levels (2006) for the current new car fleet are at around $165 \mathrm{gCO}_{2} / \mathrm{km}$ and heavy goods vehicles (HGVs) (fully loaded) at $1100 \mathrm{gCO}_{2} / \mathrm{km}$.

- PP14 Slower speeds and ecological driving (medium): this has a major impact, representing $20 \mathrm{mph}$ speed limits in all major towns and $50 \mathrm{mph}$ speed limits on all rural single-carriageway roads; lower speed limits are supported by variable signage and enforcement. There is also a targeted public education campaign concerning ecological driving skills. This package achieves a 5\% reduction in $\mathrm{CO}_{2}$ emissions.

- PP15 Freight (medium): HGV freight movements represent over $20 \%$ of traffic on key routes in Oxfordshire, particularly the $\mathrm{A} 34$ and $\mathrm{M} 40$, and vehicles are high $\mathrm{CO}_{2}$ emitters. An assumed increase in rail freight capacity between the south coast ports at Southampton and the Midlands and North, together with advisory HGV routing, would reduce heavy goods vehicle traffic through the county. This package also achieves a $5 \%$ reduction in $\mathrm{CO}_{2}$ emissions.

The other selected policy packages also have a significant impact on $\mathrm{CO}_{2}$ emissions, but the scales of impacts are less. PP1 Rail (medium), PP2 Bus (medium), PP3 Walk (high), PP4 Cycle (high), PP6 TDM/Active Traffic Management (medium), PP7 Pricing (medium), PP8 Parking Management (medium), PP9 Park and Ride (medium), PP10 Land Use Planning (medium), PP11 Behavioural Change (medium), and PP16 Long Distance Travel Substitution (medium), for example, all lead to some $\mathrm{CO}_{2}$ emission reductions. In some cases, expected impacts are masked by other traffic filling up the space gained in network improvements. The major gains are made when car and freight emissions are tackled (the vast majority of current emissions). But the wider policy areas are also very important: PPs 1-4, 6-11 and 16 lead to a level of $\mathrm{CO}_{2}$ reduction and they are also useful for non $\mathrm{CO}_{2}$ issues, such as supporting social, health and wider quality of life objectives. Although the current WebTAG appraisal is wide-reaching, it less useful in terms of picking up the intangible, yet often important, impacts.

The actual modelling assumptions are also critical to the appraisal. For example, the initial specification of road pricing (PP7) on the major strategic roads in Oxfordshire actually led to an increase in travel and emissions, as traffic was apparently diverted onto the non-strategic highway (rural roads) and longer travel distances arose. This again provides a useful lesson in terms of process - INTRA-SIM allows a speedy comparison of likely outputs from a series 
of interventions. Unsuitable impacts (and perhaps intervention definition) can be revisited and remodelled. In this case, a distance-based charge for the complete network, and perhaps better still an emissions-based charge ${ }^{6}$, would lead to a reduction in travel and emissions. Hence the process can be iterative, where interventions are redefined to optimise the achievement against objectives. This is a critical element of objectives-based strategy development.

An integrative assessment of potential transport futures is important. Feasibly some scenarios may be very beneficial in $\mathrm{CO}_{2}$ reduction terms, but do less for social or economic objectives. Multi-criteria appraisal allows us to 'read across' the different metrics. For space reasons, just five of the available indicators are discussed here $-\mathrm{CO}_{2}$ emissions (strategic environment), daily junction delay (a proxy for the economy ${ }^{7}$ ), accessibility by train (social), carbon monoxide (local environment) and road fatalities (safety). Wider impacts can be assessed using a full MCA framework. Figures 6-9 show the wider sustainability impacts, with numeric results in Table 3. A number of comments can be made:

- Daily junction delay: reduces in aggregate (by $-32,000$ aggregate seconds, or $-20.8 \%$ relative to BAU in 2030) hence traffic is viewed as travelling more 'smoothly' with less delay at junctions.

- Accessibility by rail to town centres: much increased accessibility in the areas surrounding the mainline rail network (Reading-Oxford-Midlands) and assumed new networks (Cotswold line upgrade; Evergreen 3, Oxford-Bicester-London Marylebone; and East-West Rail, Oxford-Milton Keynes-Cambridge-Felixstowe) with an increase in accessibility of $28.3 \%$ relative to BAU in 2030 .

- Carbon monoxide: reductions are made virtually across the whole county with the exceptions of clustered increases in some of the urban areas. There is a reduction of $-5,399,618 \mathrm{kgCO}$, or $-41.4 \%$ relative to BAU in 2030.

- Safety: road fatalities reduce by -23 persons, or $-15.0 \%$ relative to BAU in 2030 .

\section{INSERT FIGURE 5 HERE}

\section{INSERT FIGURES 6-9 HERE}

The spatial mapping of the distribution of $\mathrm{CO}_{2}$ emissions across the county (Figure 5) again shows major gains made in the rural and car dependent areas. The results show the chosen scenario relative to $\mathrm{BAU}$ in 2030. Overall, the $\mathrm{CO}_{2}$ target gets close to the $50 \%$ (2030) nationally set reduction targets and similar levels of reductions are achieved in emissions of other local pollutants (CO). It also has a range of additional advantages as there are improvements in accessibility, reductions in junction delays and road fatalities. This would suggest that when a full evaluation of the costs and benefits is carried out, there may be a substantial case for the implementation of this package of measures.

\footnotetext{
${ }^{6}$ The idea here is to charge vehicles by distance travelled and type of vehicle, so that the heavier, more polluting vehicles pay more. This orientates road pricing more to the reduction of $\mathrm{CO}_{2}$ emissions.

${ }^{7}$ This metric is problematic. Junction delay (and annual car time) is often correlated to other economic indicators such as GDP, with less delay seen as positive for the economy. However, impacts are often indirect at best, and using such an indicator by itself may mean that measures to reduce $\mathrm{CO}_{2}$ emissions are not viewed 'positively' in economic terms. Hence a wide-ranging MCA analysis is required (Table 1) and much care is required in interpreting results.
} 


\section{Conclusions}

The transport sector needs new approaches to demonstrate and discuss the potential pathways towards sustainable transport, including deep 'trend-break' reductions in $\mathrm{CO}_{2}$ emissions and other indicators of sustainable transport. This is ever more so when there are severe funding constraints, and where investment options are subject to greater scrutiny. There is an emerging set of methodologies, including scenario analysis, which can be combined with the more conventional approaches such as MCA, offering much promise for the evaluation and eventual implementation of sustainable transport futures. This paper has proposed a hybrid methodology that combines scenario testing, MCA, multi-actor participation and visualisation/simulation techniques, so that comparison of multiple sustainable transport scenarios against MCA impacts can take place. The results from the Oxfordshire case study provide a clear illustration of the process, and there are several more general lessons that can be learned. The geography of the county, the historic and compact central city (Oxford, with good levels of walking, cycling and public transport), and a surrounding periphery which is much more dispersed and car dependent, are all typical to many city-regions in the UK and elsewhere. Some concluding comments are made:

1. An integrated approach to transport policy making is important, seeking to achieve positive outcomes against multiple policy goals, including $\mathrm{CO}_{2}$ reductions. Diverse impacts, some of which may act in different directions, are difficult to appreciate and weigh in terms of importance. A scenario and MCA tool, such as INTRA-SIM, offers one way forward in allowing a more speedy and transparent decision-making process. Depending on the composition of the scenarios considered, impacts are likely to vary substantially relative to economic, social and environmental goals.

2. The inclusion of a wide range of policy options is required to achieve significant progress towards sustainable travel behaviours, including low emission vehicles, alternative fuels, rail, bus, walk, cycle, behavioural change, slower speeds, freight planning, spatial planning, etc. An important issue is the level of responsibility insofar as where decisions need to be taken. The interventions considered cover those within the remit of Oxfordshire County Council and other key public and private decision makers, including the national and European levels.

3. More significant movement against wider sustainability goals would require moving towards the 'high level' of application of the policy packages, and probably beyond those considered here. This may mean more radical measures and initiatives (for the present day), such as new local rail links, a light rapid transit network for Oxford, tram-train services (e.g. serving Reading-Abingdon-Oxford), fare level changes; much more extensive bus services in rural areas, bus rapid transit (e.g. serving Oxford and other key centres), taxi-bus type schemes for rural areas; a much improved public realm for pedestrians; cycle networks and hire facilities across the county; road pricing (at a high charge per kilometre); car free developments, higher parking charges and restrictions in parking supply; much extended park and ride with 'remote' parking sites next to major routes; spatial planning shaped to support public transport usage, walking and cycling to a much greater extent than at present; widespread, mass market smarter choice behavioural measures; and slower speed limits on all 
roads. Many of these have been modelled in the Oxfordshire context, and offer deeper $\mathrm{CO}_{2}$ reduction potential and many other sustainability benefits.

4. Policy options and schemes can be iteratively redefined to achieve the stated policy objectives through a different specification, changes in network routeing, a tightening of legislation, or improvements in incentives. Multiple simulations provide opportunities for different stakeholders to explore the possible implications of particular policy options.

5. Scenario costs (particularly in view of current funding constraints within the transport sector) would provide an additional dimension to the analysis, as would progress against targets or indicators, as well as issues relating to political and public acceptability and implementation. Often the 'optimum theoretical' strategies fail because little consideration is given to deliverability issues, as illustrated by much of the experience in introducing road pricing regimes. Perhaps political and public acceptability should be considered first (and a consensus produced), before the technical work is undertaken. The use of MCA also offers the potential to weight objectives and criteria, including changes in weighting over time, hence assisting in the achievement of the 'important' strategic societal goals (Saxena, 2012; Hickman et al, 2009c), and this can then be included in a more formal evaluation of the costs and benefits of each set of policy packages that meet the scenario objectives.

Some problematic issues remain. The radical measures considered above in point 3 seem attractive to many transport planners, yet most of them are impossible to deliver in the current public and political climate. Perhaps the solution is for a much greater focus on preparing and communicating a consensus - the 'strategic conversation' (Van der Heijden, 1996) - concerning the key strategic issues and controversial decision points against strategic goals achievement. Detailed appraisal and cost-benefit analysis is then used to justify and work through the details of this strategic decision, rather than making the strategic decision. The analysis presented above is carried out against five impact indicators, and this could be extended to include more issues, but a balance needs to be struck between the number of key indicators, their importance, and excess detail. The ones used here were developed in consultation with Oxford County Council in the context of their Local Transport Plan (2011-2030). Decision-making tools offer a way forward for appraisal and integrated strategy development as an aid to evaluation and transparency in decision-making. Their design, of course, raises important questions insofar as whose preferences matter, in this case in terms of assembling policy measures, packages, scenarios and appraisal frameworks. Such questions are important technically and also in terms of deliverability.

The evidence used in this paper is very much from the UK context, but the lessons learnt potentially have much wider applicability. The challenge of contributing to wide-ranging societal goals in the transport sector means substantial progress has to be made against current trends. Taleb (2007) suggests that "we shouldn't drive the school bus blindfolded"; and this certainly resonates in terms of examining the possibilities within our unfolding transport futures.

Acknowledgements: many thanks to Oxfordshire County Council (Jo Fellows and Roger O'Neill) who provided funding for the Oxfordshire INTRA-SIM study and assisted in the work, 
and the wider study team who have helped in the modelling and analysis - from the Halcrow Group (including Catherine Seaborn, Wambui Gachaco, Gareth Walters and Will Saltmarsh). Others from Oxford University, Transport Studies Unit have provided useful comments. The authors also thank the reviewers for very useful and constructive comments. The views expressed in this article are of course from the authors and do not necessarily reflect those of the project funders or other organisations involved.

\section{References}

Åkerman, J. and Höjer, M. 2006. How much transport can the climate stand? Sweden on a sustainable path in 2050. Energy Policy, 34, 1944-1957.

Anable, J. and Bristow, A.L. 2007. Transport and Climate Change: Supporting Document to the CfIT Report on Transport and Climate Change. London: Commission for Integrated Transport.

Arnold, M. 1866. Thyrsis "and that sweet city with her dreaming spires", Line 19. Macmillan's Magazine.

Ashiru, O., Gachacho, W., Seaborn, C., Saltmarsh, W. and Hickman, R. 2010. Oxfordshire INTRASIM: Modelling Assumptions. London: Halcrow [available from the authors].

Banister, D., Stead, D., Steen, P., Akerman, J., Dreborg, K., Nijkamp, P. and Schleicher-Tappeser, R. 2000. European Transport Policy and Sustainable Mobility, London, Spon.

Brand, C., Tran, M. and Anable, J. (in press, 2011) The UK transport carbon model: an integrated life cycle approach to explore low carbon futures. Energy Policy.

Boarnet, M. 2010. Planning, climate change, and transportation: Thoughts on policy analysis. Transportation Research A, 44, 587-595.

Bohte, W., Maat, K. and Van Wee, B. 2009. Measuring attitudes in research on residential self selection and travel behaviour: A review of theories and empirical research. Transport Reviews, 29, 325-357.

Breheny, M. 1997. Urban compaction: Feasible and acceptable? Cities, 14, 209-217.

Bristow, A., Tight, M., Pridmore, A. and May, A. 2008. Developing pathways to low carbon land-based passenger transport in Great Britain by 2050. Energy Policy, 36, 3427-3435.

Cairns, S., Sloman, L., Newson, C., Anable, J., Kirkbride, A. and Goodwin, P. 2004. Smarter Choices: Changing the Way We Travel. London: Department for Transport.

Cambridge Systematics. 2009. Moving Cooler. An Analysis of Transportation Strategies for Reducing Greenhouse Gas Emissions. Washington: Urban Land Institute.

Cao, X., Mokhtarian, P. and Handy, S. 2009. Examining the impacts of residential self-selection on travel behaviour: A focus on empirical findings. Transport Reviews, 29, 359-395.

Cervero, R. and Kockelman, K. 1997. Travel demand and the 3Ds: Density, diversity, and design. Transportation Research D, 2, 199-219.

Department for Food and Rural Affairs (Defra). 2009. Modal $\mathrm{CO}_{2}$ Emission Factors London: Defra.

Department for the Environment, Transport and the Regions (DETR). 1998. A New Deal for Transport: Better for Everyone, White Paper London: The Stationery Office.

Department for Transport (DfT). 2008a. Delivering a Sustainable Transport Strategy (DaSTS). London: The Stationery Office.

Department for Transport (DfT). 2008b. Vehicle/Speed $\mathrm{CO}_{2}$ Emission Factors. London: Department for Transport.

Department for Transport (DfT). 2009. Guidance to Regions on Delivering a Sustainable Transport System. London: The Stationery Office.

Department for Transport. (DfT). 2010. Website for Transport Analysis Guidance (WebTAG) [Online] [accessed October 2010].

Department of Business Enterprise and Regulatory Reform (DBERR). 2008. Energy Trends. London: National Statistics.

Department of the Environment, Transport and the Regions (DETR). 2001. Planning Policy Guidance Note 13: Transport (PPG13), London: The Stationery Office.

Dodgson, J., Spackman, M., Pearman, A., Phillips, L. 2009. Multi-Criteria Analysis: A Manual. London: Department of Communities and Local Government. 
Dreborg, K. 1996. Essence of backcasting. Futures, 28, 813-828.

EU POSSUM. 1998. POSSUM: Final Report. European Community Fourth Framework Programme.

Ewing, R. and Cervero, R. 2001. Travel and the built environment. Transportation Research Record, 1780, 87-114.

Ewing, R., Bartholomew, K., Winkelman, S., Walters, J. and Chen, D. 2008. Growing Cooler: The Evidence on Urban Development and Climate Change, Urban Land Institute.

Ewing R, Cervero R. 2010. Travel and the built environment. A meta analysis. Journal of the American Planning Association, 76(3), 265-94.

Frommelt, O. C. 2008. Strategy, Scenarios and Strategic Conversation: An Exploratory Study in the European Truck Industry. DBA thesis, University of Nottingham.

Geurs, K. and Van Wee, B. 2004. Backcasting as a tool for sustainable transport policy making: The environmentally sustainable transport study in the Netherlands. European Journal of Transport Infrastructure Research, 4, 47-69.

Godot, M. 2000. The art of scenarios and strategic planning. Technological Forecasting and Social Change, 65, 3-22.

Government Office for the South East (GOSE). 2009. The South East Plan. Regional Spatial Strategy for the South East of England. Guildford: GOSE.

Greene, D. L. 1993. Transportation and energy: The global environmental challenge. Transportation Research A, 27, 163-166.

Halcrow Group. 2010. Swindon DaSTS Policy Options Review. Swindon: Halcrow.

Handy, S., Cao, X. and Mokhtarian, P. 2005. Correlation or causality between the built environment and travel behaviour? Evidence from northern California. Transportation Research D, 10, 427444.

Headicar, P. 2010. PPG13: Evidence of the strategic deficit. Town and Country Planning, February.

Hickman, R. and Banister, D. 2007. Looking over the horizon: Transport and reduced $\mathrm{CO}_{2}$ emissions in the UK by 2030. Transport Policy, 14(5), 377-387.

Hickman, R., Ashiru, O. and Banister, D. 2009a. Achieving carbon efficient transport: Backcasting from London. Transportation Research Record, 2139, 172-182.

Hickman, R., Seaborn, C., Headicar, P. and Banister, D. 2009b. Planning for Sustainable Travel. Summary Guide. London: Halcrow and CfIT.

Hickman, R., Ashiru, O., Saxena, S. and Banister, D. 2009c. Visioning and Backcasting for Transport in London. Stages 3/4 Background Report. (www.vibat.org). London: Halcrow.

Hickman, R., Ashiru, O. and Banister, D. 2010. Transport and climate change: Simulating the options for carbon reduction in London. Transport Policy, 17(2), 110-125.

Hickman, R., Seaborn, C., Headicar, P. and Banister, D. 2010. Planning for sustainable travel: Integrating spatial planning and transport. In: Givoni, M., Banister, D. (ed.) Integrated Transport: from Policy to Practice. London: Routledge.

Hughes, P. 1993. Personal Transport and the Greenhouse Effect, London, Earthscan.

Kahn, H. 1962. Thinking about the Unthinkable. Horizon Press: New York.

Kahn, H., Wiener, A.J. 1967. The Year 2000: A Framework for Speculation on the Next Thirty Three Years. New York, Macmillan.

Levinson, D. M. and Krizek, K. J. 2008. Planning for Place and Plexus: Metropolitan Land Use and Transport. New York, Routledge.

Lindblom, C. E. 1959. The science of muddling through. Public Administration Review, 19, 79-88.

Litman, T. 2010. Transportation Demand Management (TDM) Encyclopedia [Online]. Victoria Transport Policy Institute [accessed October 2010].

Lucas, K. and Scott, L. 2010. Forward Thinking for Local Transport in Oxfordshire to 2030 and Beyond. Oxford: TSU. Report for Oxfordshire County Council.

Macharis, C., De Witte, A. and Turcksin, L. 2010. The multi-actor multi-criteria analysis (MAMCA) Application in the Flemish long-term decision making process on mobility and logistics. Transport Policy, 17(5): 303-311.

Mackay, D. 2009. Sustainable Energy - Without the Hot Air, Cambridge, UIT.

Mckinnon, A. 2007. CO2 Emissions from Freight Transport in the UK. Background Report. London: Commission for Integrated Transport.

Mckinnon, A. 2005. The economic and environmental benefits of increasing maximum truck weight: the British experience. Transportation Research D, 10, 77-95. 
Newman, P. and Kenworthy, J. 1999. Sustainability and Cities: Overcoming Automobile Dependence, Washington, D.C. , Island Press.

Niemeier, D. Gould, G., Karner, A., Hixson, M., Bachmann, B., Okma, C., Lang, Z., and Heres Del Valle, D. 2008. Rethinking downstream regulation: California's opportunity to engage households in reducing greenhouse gases. Energy Policy, 36(9), 3436-47.

Organisation for Economic Co-operation and Development (OECD). 2000. EST! Environmentally Sustainable Transport. Futures, Strategies and Best Practice. Synthesis Report. Paris: OECD.

Oxfordshire County Council (OCC). 2010. Population Estimate, Oxfordshire. [online] www.oxfordshire.gov.uk/cms/public-site/about-oxfordshire [accessed October 2010]

Oxfordshire County Council (OCC). 2007. Population Estimate, Oxford.

Pacala, S. and Socolow, R. 2004. Stabilization wedges: solving the climate problem for the next 50 years with current technologies. Science, 305, 968-972.

Popper, K. R. 1957. The Poverty of Historicism. London: Routledge and Kegan Paul.

Pridmore, A., Bristow, A., May, T. and Tight, M. 2003. Climate Change, Impacts, Future Scenarios and the Role of Transport. Leeds: ITS and Tyndall Centre.

Robinson, J. B. 1982. Energy backcasting: A proposed method of policy analysis. Energy Policy, 10, 337-344.

Robinson, J. B. 1990. Futures under glass: A recipe for people who hate to predict. Futures, 22, 820842.

Royal Commission on Environmental Pollution (RCEP). 1994. Transport and the Environment, 18th Report. Cm 2674. London: HMSO.

Santos, G., Behrendt, H. and Teytelboym, A. 2010. Part II: Policy instruments for sustainable road transport. Research in Transportation Economics, 28, 46-91.

Saxena, S. 2012. Low Carbon Transport Pathways in Delhi. DPhil (under submission), University of Oxford

Schäfer, A. and Victor, D. G. 2000. The future mobility of the world population. Transportation Research Part A, 34, 171-205.

Schäfer, A., Heywood, J.B., Jacoby, H.D. and Waitz, I.A. 2009. Transportation in a ClimateConstrained World, Cambridge, Mass.: MIT.

Schipper, L. and Meyers, S. 1993. Using scenarios to explore future energy demand in industrialized countries. Energy Policy, 21, 264-275.

Schipper, L., Marie-Lilliu, C. and Gorham, R. 2000. Flexing the Link Between Transport and Greenhouse Gas Emissions. A Path for the World Bank. Paris: IEA.

Schwanen, T. and Mokhtarian, P. 2005. What if you live in the wrong neighbourhood? The impact of residential neighbourhood type dissonance on distance travelled. Transportation Research A, 10(2):127-51.

Schwanen, T., Banister, D., Anable, J. 2011. Scientific research about climate change mitigation in transport: A critical review. Transportation Research A, 45, 993-1006.

Schwartz, P. 1996. The Art of the Long View: Paths to Strategic Insight for Yourself and Your Company, New York. London: Currency Doubleday.

Seaborn, C., O'Brien, C. Clegg, J., and O'Neill, R. 2009. Oxfordshire LTP3: Policy Options and Packages. Working Paper. London: Halcrow Group.

Shiftan, Y., Kaplan, S. and Hakkert, S. 2003. Scenario building as a tool for planning a sustainable transportation system. Transportation Research D, 8, 323-342.

Simon, H. A. 1955. A behavioural model of rational choice. Quarterly Journal of Economics, 69, 99118.

Simons, D. J. and Chabris, C.F. 1999. Gorillas in the midst: Sustained international blindness for dynamic events. Perception, 28, 1059-1074.

Sperling, D.and Gordon, D. 2009. Two Billion Cars. Driving toward Sustainability. New York: Oxford University Press.

Stanley, J., Hensher, D. and Loader, C. 2011. Road transport and climate change: Stepping off the greenhouse gas. Transportation Research A, 45(10), 1020-1030.

Taleb, N. 2007. The Black Swan: The Impact of the Highly Improbable. London, Penguin.

Van der Heijden, K. 1996. Scenarios: The Art of Strategic Conversation, Chichester: John Wiley.

Wack, P. 1985. Scenarios: Unchartered Waters Ahead. Harvard Business Review, September, 73-89. 
Yang, C., McCollum, D., McCarthy, R. and Leighty, W. 2009. Meeting an $80 \%$ reduction in greenhouse gas emissions from transportation by 2050: A case study in California. Transportation Research D, 14, 147-156. 


\section{TABLES}

Table 1: MCA Framework Indicators

\begin{tabular}{|c|c|c|c|c|}
\hline $\begin{array}{c}\text { Environment } \\
\text { (Strategic) }\end{array}$ & Environment (Local) & Accessibility & Safety & Economy \\
\hline $\begin{array}{l}\text { - Total } \mathrm{CO}_{2} \\
\text { emissions by } \\
\text { car, LGV, HGV, } \\
\text { bus and rail(*) }\end{array}$ & $\begin{array}{l}\text { - Population affected } \\
\text { by noise } \\
\text { - Number of } \\
\text { households } \\
\text { experiencing noise } \\
\text { levels above 68db } \\
\text { - Population } \\
\text { perceiving a noise } \\
\text { nuisance } \\
\text { - Population } \\
\text { experiencing } \\
\text { vibration } \\
\text { - Number of } \\
\text { households } \\
\text { experiencing } \\
\text { vibration } \\
\text { - Local air quality } \\
\text { impacts (by carbon } \\
\text { monoxide }\left(^{*}\right) \text {, } \\
\text { nitrogen dioxide, } \\
\text { ozone, sulphur } \\
\text { dioxide, } \\
\text { particulates) }\end{array}$ & $\begin{array}{l}\text { - Hansen measure of } \\
\text { accessibility to } \\
\text { Town Centres by } \\
\text { mode }\left(^{*}\right) \\
\text { - Hansen measure of } \\
\text { accessibility to } \\
\text { Hospitals by mode } \\
\text { - Hansen measure of } \\
\text { accessibility to } \\
\text { Workplaces by } \\
\text { mode } \\
\text { - } 2026 \text { Households } \\
\text { within } 30 \text { minutes of } \\
\text { Town Centres by } \\
\text { mode } \\
\text { - } 2026 \text { Households } \\
\text { within } 30 \text { minutes of } \\
\text { Hospitals by mode } \\
2026 \text { Households } \\
\text { within } 30 \text { minutes of } \\
\text { Workplaces by } \\
\text { mode }\end{array}$ & $\begin{array}{l}\text { - Number of } \\
\text { personal injury } \\
\text { accidents } \\
\text { (PIAs), based on } \\
\text { Stats } 19 \text { data } \\
\text { (2007) } \\
\text { - Number of } \\
\text { accidents } \\
\text { resulting in slight } \\
\text { injury } \\
\text { - Number of } \\
\text { accidents } \\
\text { resulting in } \\
\text { serious injury } \\
\text { - Number of } \\
\text { accidents } \\
\text { involving } \\
\text { fatalities }\left(^{*}\right)\end{array}$ & $\begin{array}{l}\text { - Journey time } \\
\text { reliability } \\
\text { - Junction } \\
\text { delays }\left(^{*}\right) \\
\text { - Travel time on } \\
\text { links, by mode } \\
\text { - Access to jobs }\end{array}$ \\
\hline
\end{tabular}

*Only partial reporting of the indicators is possible in this paper. The $\left({ }^{*}\right)$ notation illustrates the indicators used in the later analysis. 
Table 2: Scenario 1 'Satisficing with Technology'

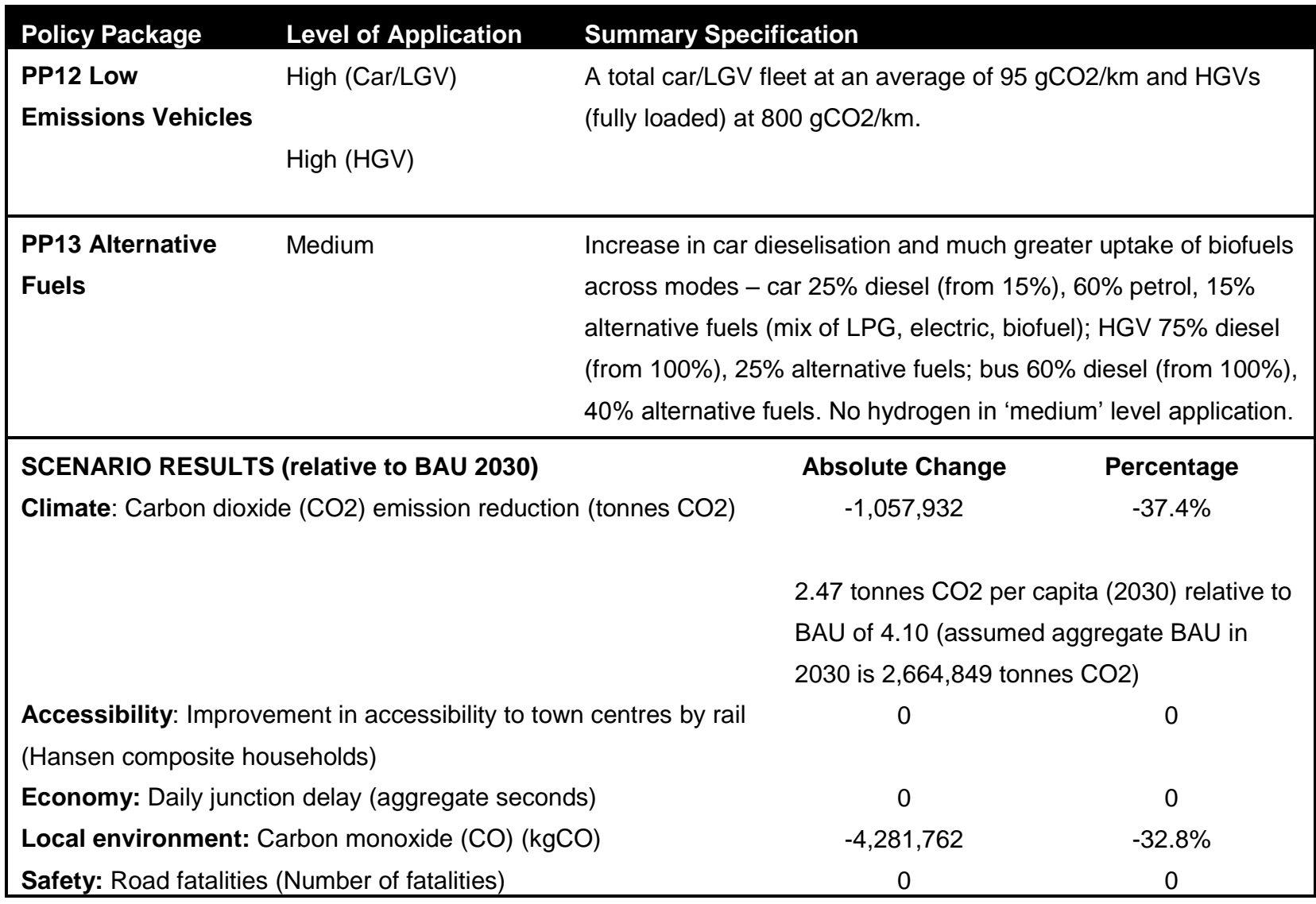

Note. Preliminary modelling results 2010. The modelling is based on individual model runs for each level of application of a policy package. MCA indicator impacts are derived from travel distance, mode share and speed outputs. Additivity is assumed between packages. Clearly this omits potential super-additivity (synergy) and subadditivity (double counting) effects. This is an area for further research by the study team in terms of methods of optimising packaging process and modelling. Initial thoughts on synergies are given in Hickman et al. (2009a). 
Table 3: Scenario 2 ‘Sustainable Mobility’

\begin{tabular}{|c|c|c|}
\hline Policy Package & Level of Application & Summary Specification \\
\hline PP1 Rail & Medium & $\begin{array}{l}\text { Interchange improvements, Mainline network frequency } \\
\text { upgrades (Reading-Oxford-Midlands) and assumed new } \\
\text { networks (Cotswold line upgrade; Evergreen 3, Oxford-Bicester- } \\
\text { London Marylebone; and East-West rail, Oxford-Milton Keynes- } \\
\text { Cambridge-Felixstowe), new Milton Park station. }\end{array}$ \\
\hline PP2 Bus & Medium & $\begin{array}{l}\text { Improved Premium Routes to main housing and employment } \\
\text { sites; improved bus services between large towns and small } \\
\text { towns; electric and hybrid buses in Oxford. }\end{array}$ \\
\hline PP3 Walk & High & $\begin{array}{l}\text { High quality pedestrian environment and streetscape upgrades } \\
\text { in Oxford, larger towns, smaller towns and villages, and } \\
\text { connections to Rights of Way network. }\end{array}$ \\
\hline PP4 Cycle & High & $\begin{array}{l}\text { High quality network improvements, integrated cycle parking in } \\
\text { Oxford, larger towns, smaller towns and villages, cycle hire } \\
\text { schemes in Oxford and large towns. New links from new } \\
\text { developments. }\end{array}$ \\
\hline $\begin{array}{l}\text { PP5 Highway } \\
\text { Infrastructure }\end{array}$ & BAU & None \\
\hline $\begin{array}{l}\text { PP6 TDM/Active } \\
\text { Traffic Management }\end{array}$ & Medium & $\begin{array}{l}\text { Access to Oxford programme, including HOV lane on A34; } \\
\text { routeing measures from Transport Networks Review (TNR); } \\
\text { Traffic Incident Management (TIM) programme; expansion of } \\
\text { real-time monitoring systems across the county. }\end{array}$ \\
\hline PP7 Pricing & Medium & $\begin{array}{l}\text { Road pricing scheme across Oxfordshire and the UK, charging } \\
20 \text { p per kilometre for all vehicles. }\end{array}$ \\
\hline $\begin{array}{l}\text { PP8 Parking } \\
\text { Management }\end{array}$ & Medium & $\begin{array}{l}\text { Reduced parking supply in new developments and maximum } \\
\text { standards applied, increased use of controlled parking zones. }\end{array}$ \\
\hline PP9 Park and Ride & Medium & $\begin{array}{l}\text { Increase capacity at existing sites: Seacourt, Redbridge, } \\
\text { Thornhill; new remote park and ride sites for Oxford on A34(s), } \\
\text { A40(w) and A34(n)/A41 corridors, used for accessing Premium } \\
\text { Bus Routes. }\end{array}$ \\
\hline $\begin{array}{l}\text { PP10 Land Use } \\
\text { Planning }\end{array}$ & Medium & $\begin{array}{l}\text { Development located according to South East Plan but better } \\
\text { strategic co-ordination and sustainability travel aspirations } \\
\text { achieve } 25 \% \text { lower car trip rates in new developments. }\end{array}$ \\
\hline $\begin{array}{l}\text { PP11 Smarter } \\
\text { Choice Behavioural } \\
\text { Measures }\end{array}$ & Medium & $\begin{array}{l}\text { Enhanced travel planning (workplace and schools), widespread } \\
\text { travel awareness campaign including increased availability of } \\
\text { pre-trip and en-route information, personalised travel planning in } \\
\text { new developments, support for car clubs. }\end{array}$ \\
\hline $\begin{array}{l}\text { PP12 Low } \\
\text { Emissions Vehicles }\end{array}$ & $\begin{array}{l}\text { High (Car/LGV) } \\
\text { High (HGV) }\end{array}$ & $\begin{array}{l}\text { A total car/LGV fleet at an average of } 95 \mathrm{gCO} 2 / \mathrm{km} \text { and } \mathrm{HGVs} \\
\text { (fully loaded) at } 800 \mathrm{gCO} 2 / \mathrm{km} \text {. }\end{array}$ \\
\hline
\end{tabular}




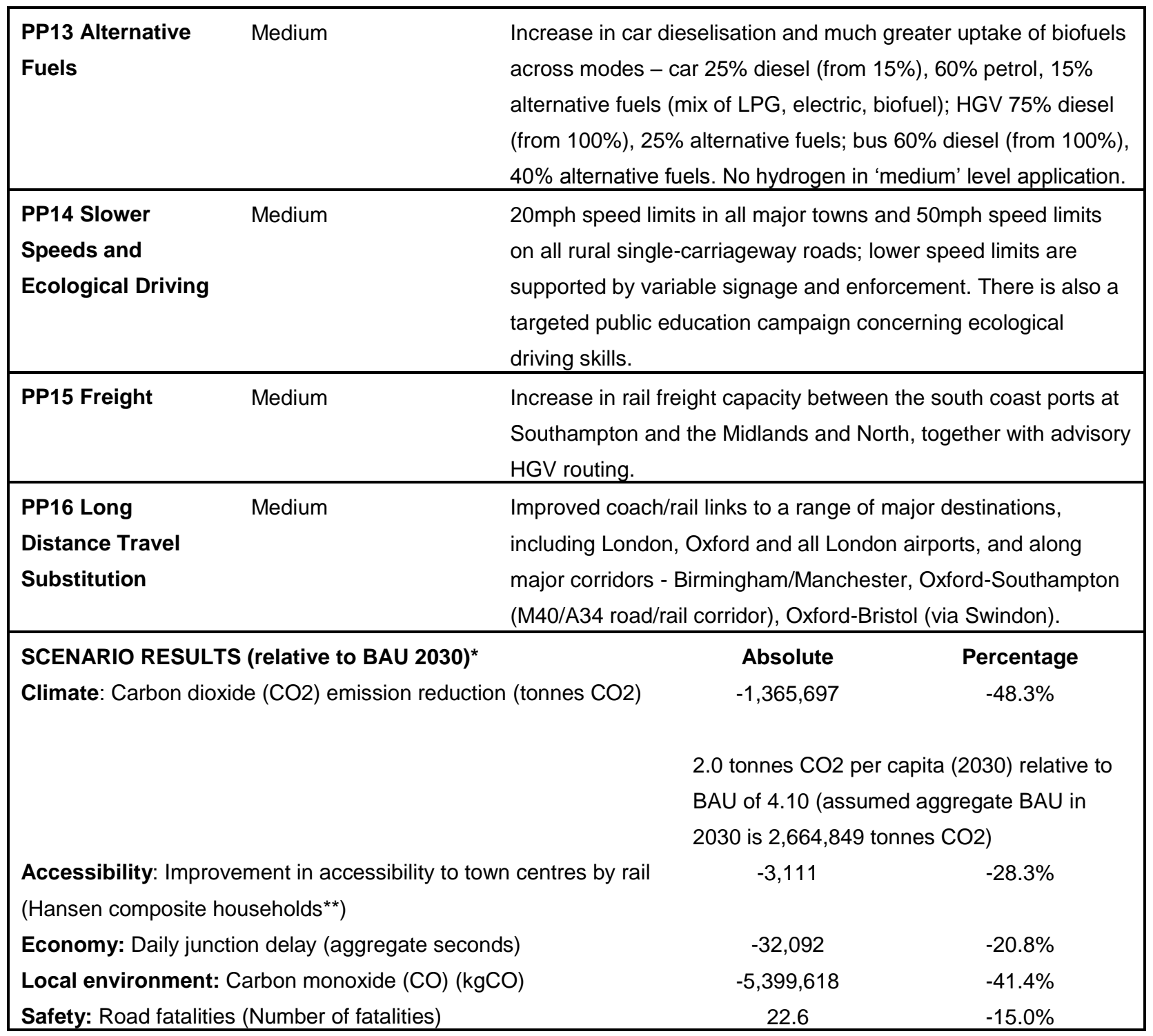

Notes.

*Preliminary modelling results 2010. The modelling is based on individual model runs for each level of application of a policy package. MCA indicator impacts are derived from travel distance, mode share and speed outputs. **Hansen composite measures are well used in accessibility planning. They measure accessibility for a given sub-area (in this case Oxfordshire) to all other sub-areas (all town centres in Oxfordshire). 


\section{FIGURES}

Figure 1: The Oxfordshire Study Area

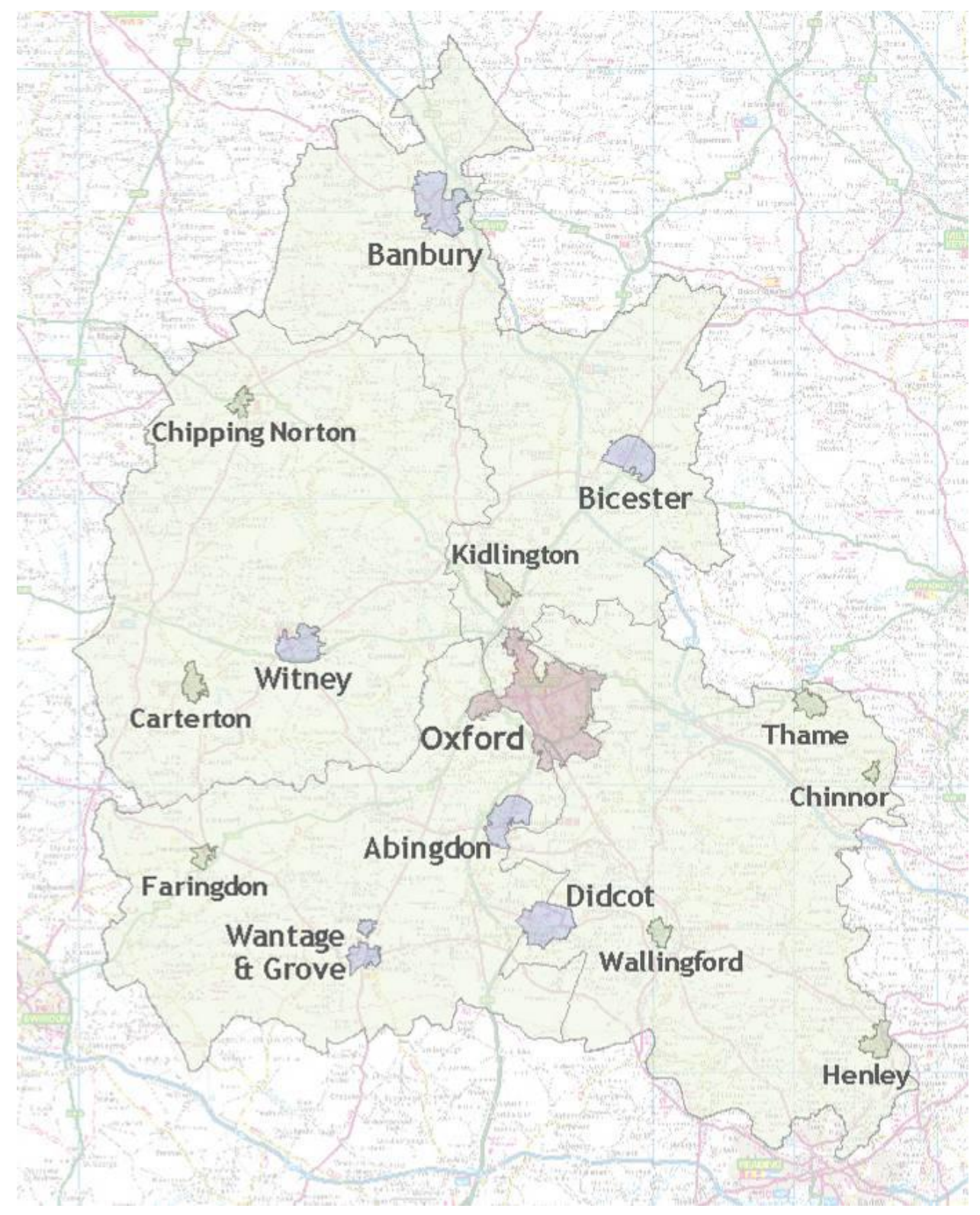

0 $10 \mathrm{~km}$ 
Figure 2: A Systematic 'Sifting' of Available Measures

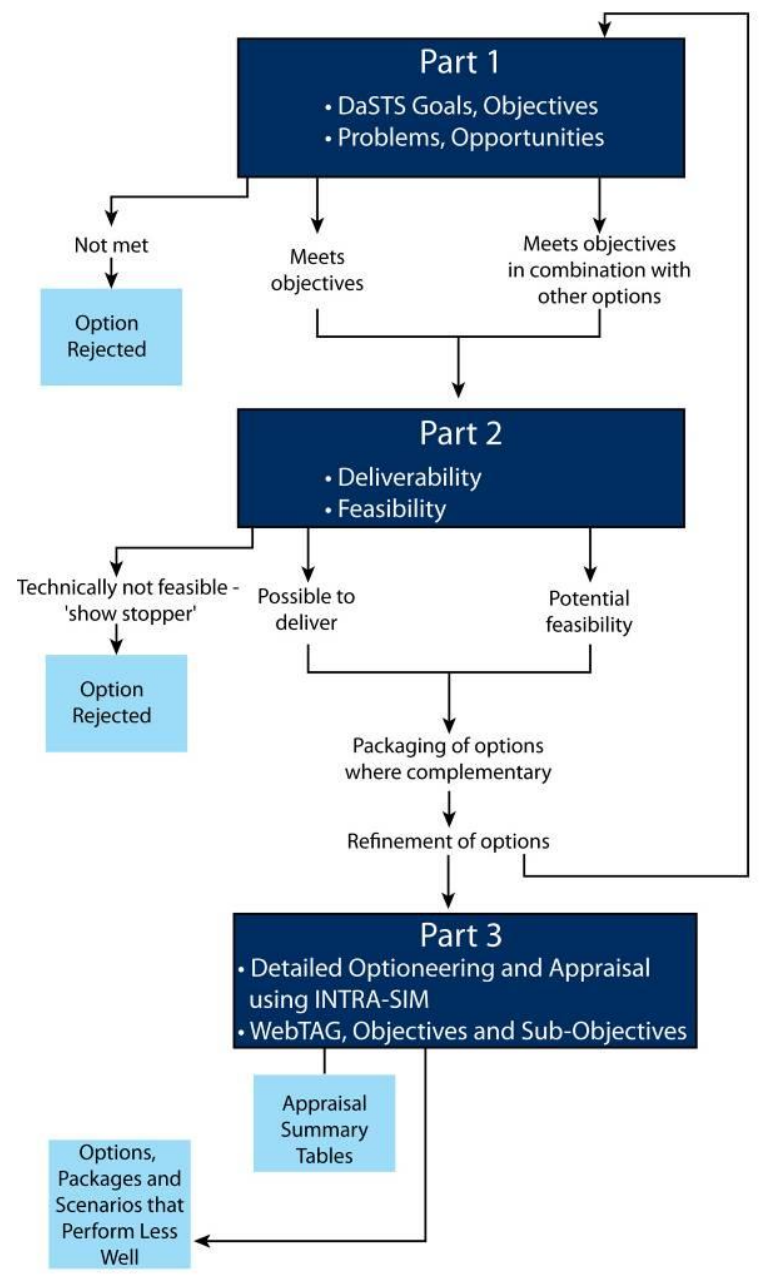


Figure 3: Developing Scenarios and MCA

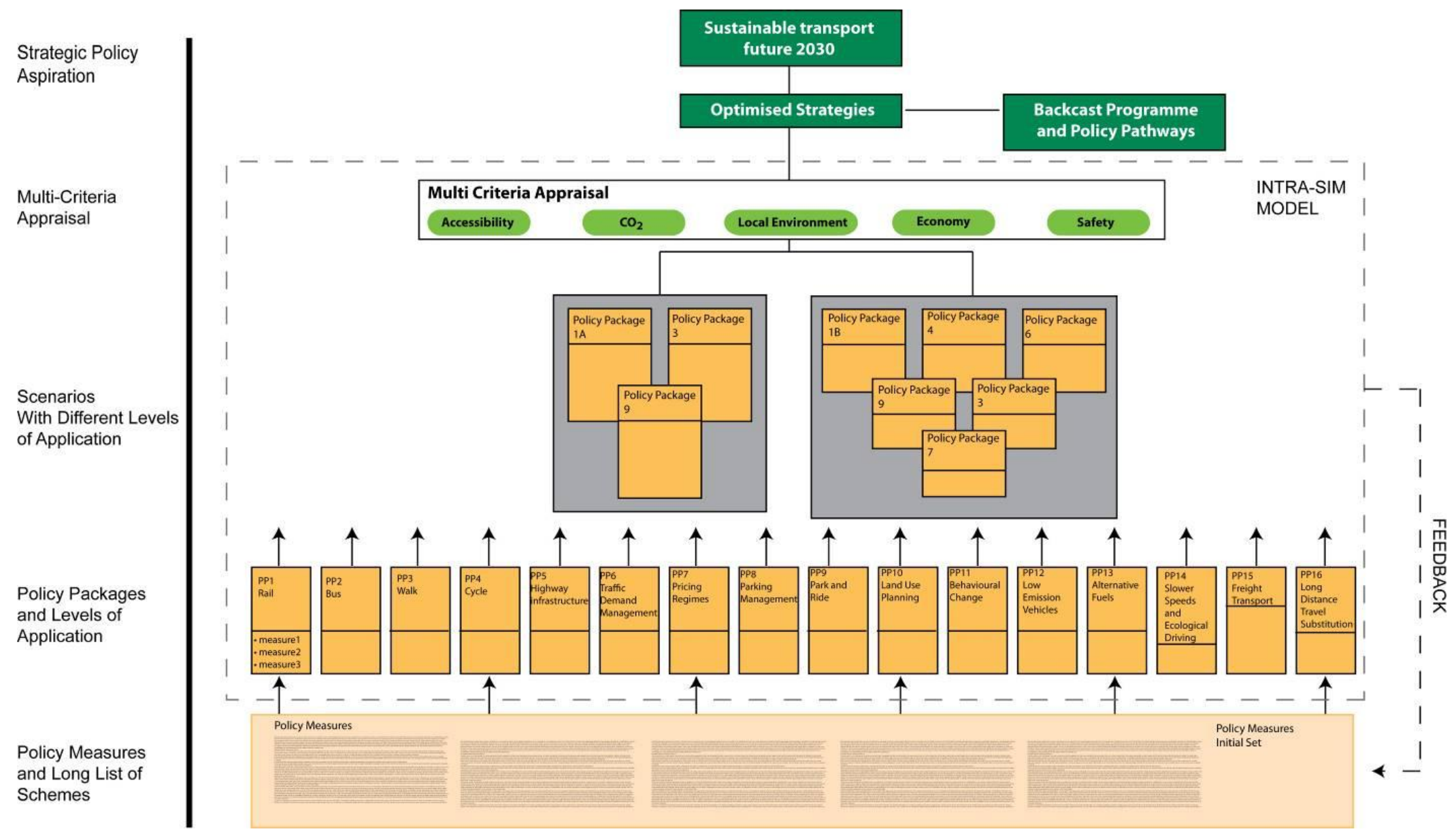


Figure 4: Scenario 1 'Satisficing with Technology' - Spatial CO2 Emissions

\section{INTRASIM OXFORDSHIRE}

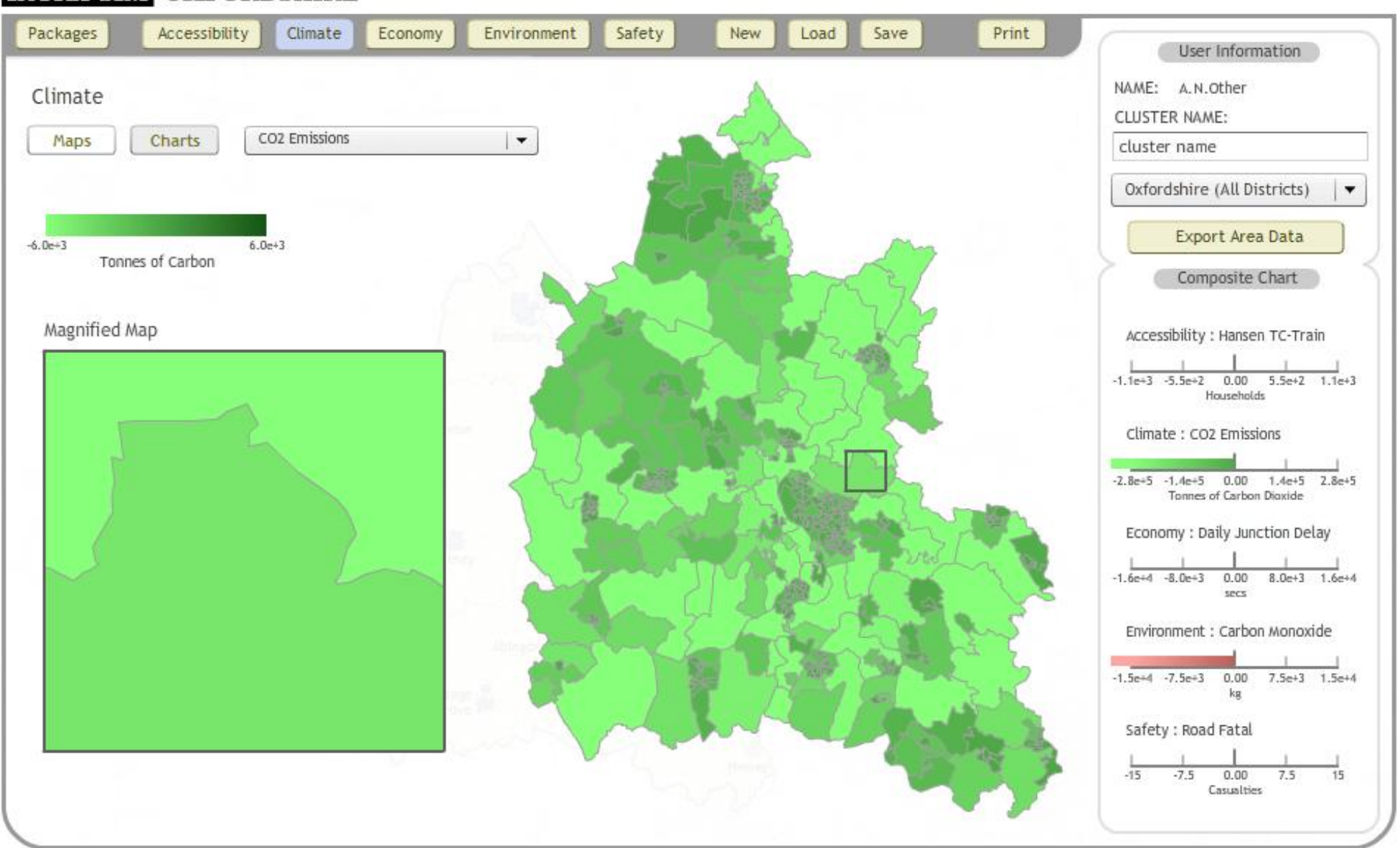


Figure 5: Scenario 2 'Sustainable Mobility' - Spatial CO2 Emissions

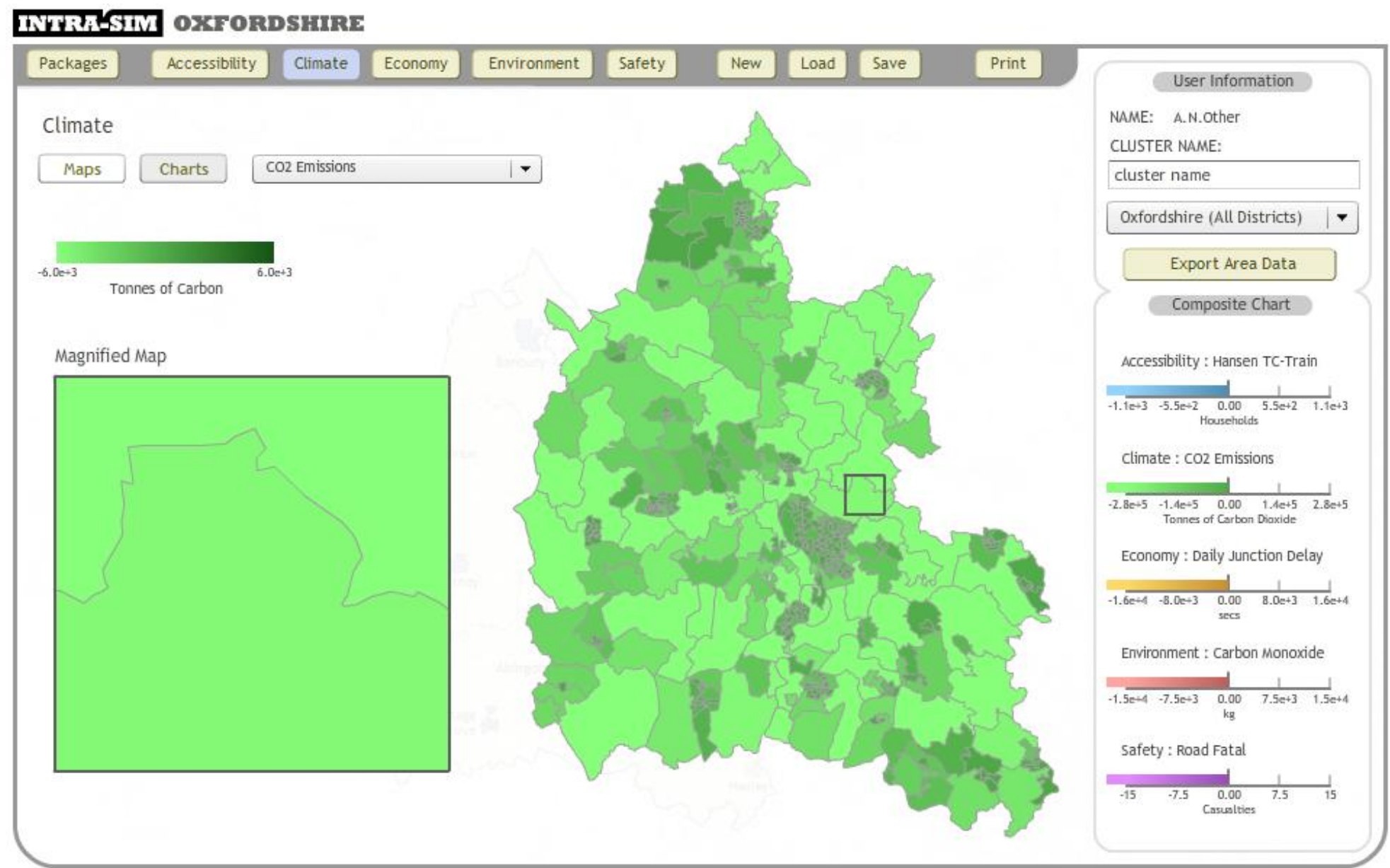


Figure 6: Scenario 2 'Sustainable Mobility' - Economy (Daily Junction Delay)

INTRASIM OXFORDSHRE

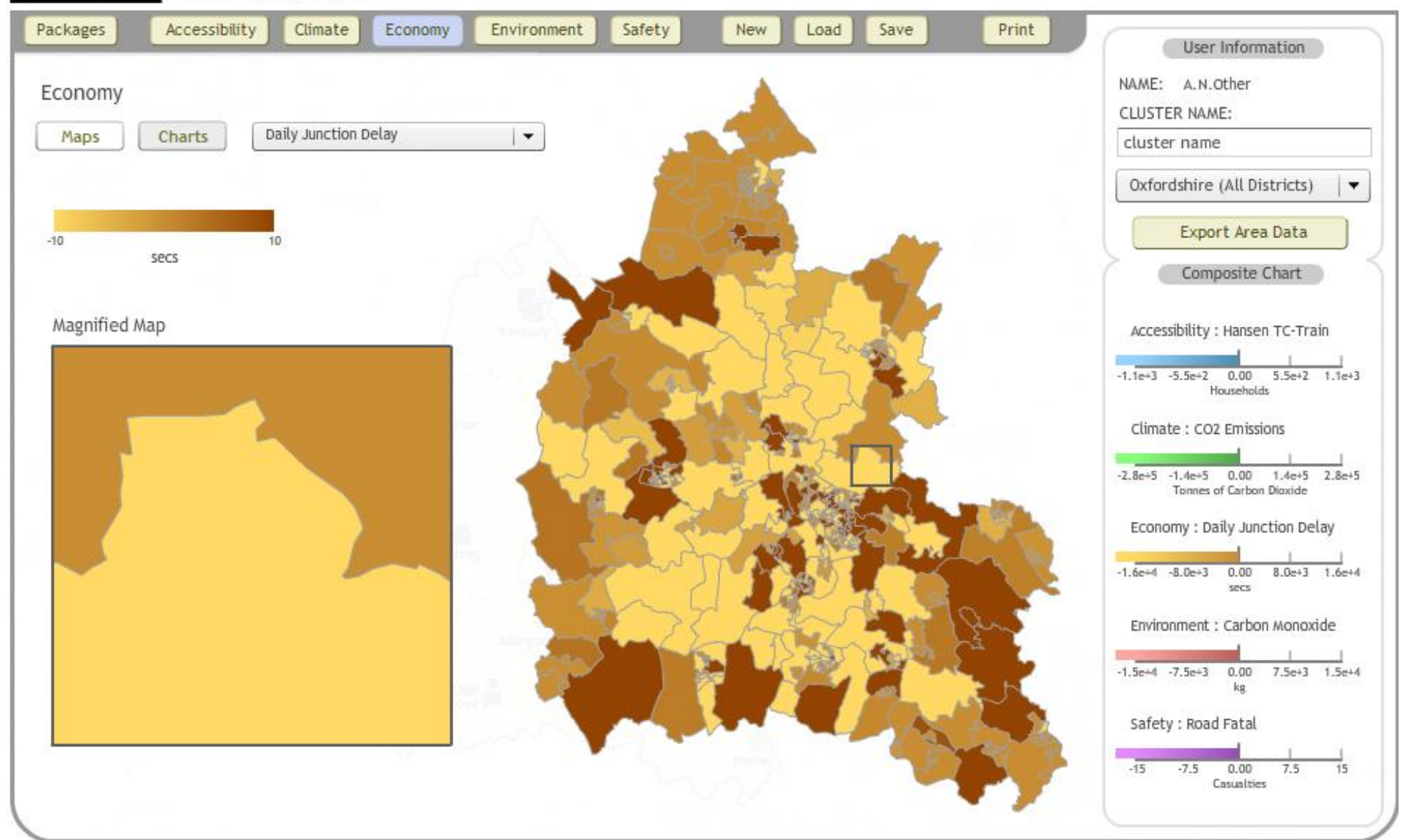


Figure 7: Scenario 2 'Sustainable Mobility' - Social (Accessibility by Train)

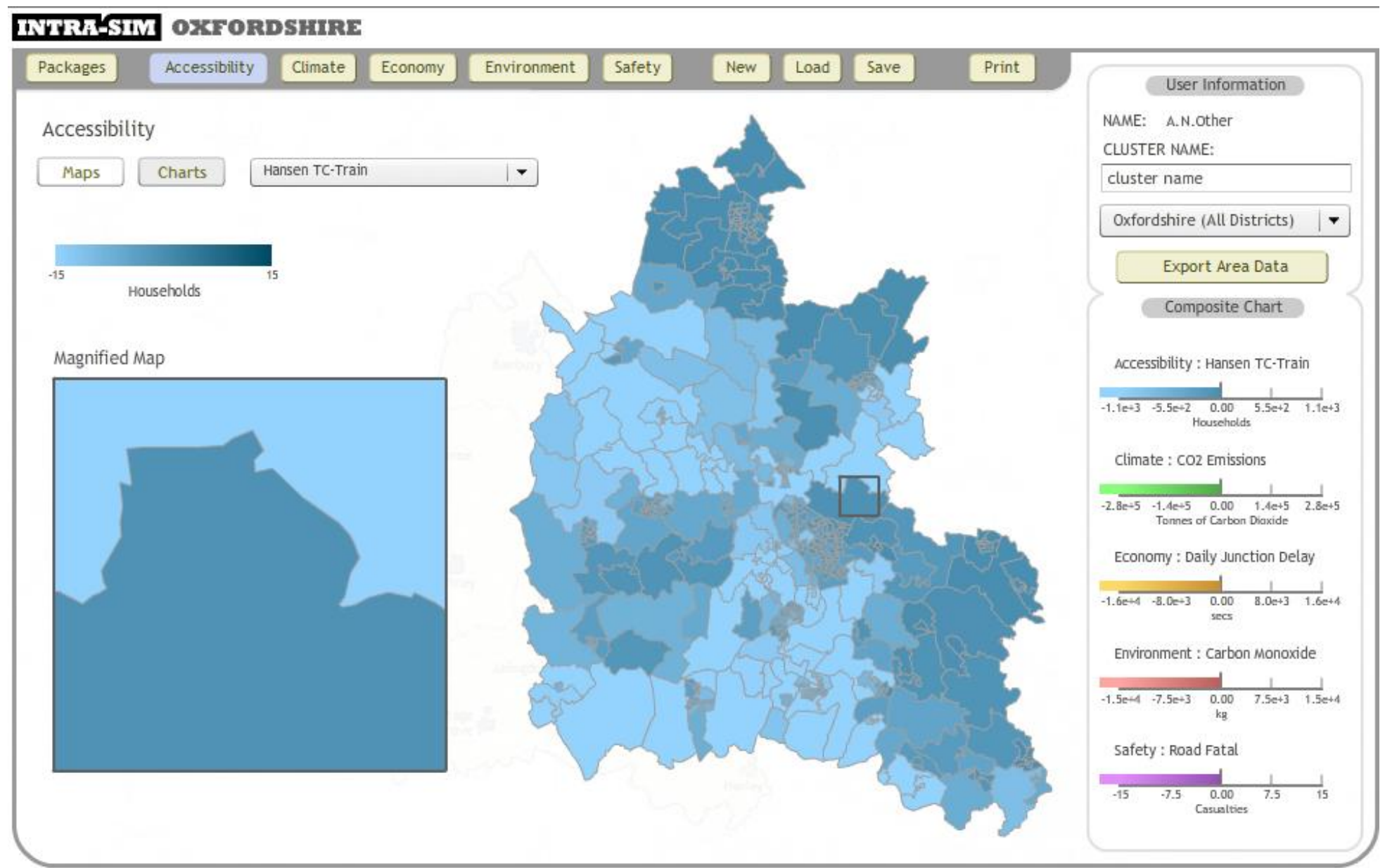


Figure 8: Scenario 2 'Sustainable Mobility’ - Local Environment (Carbon Monoxide)

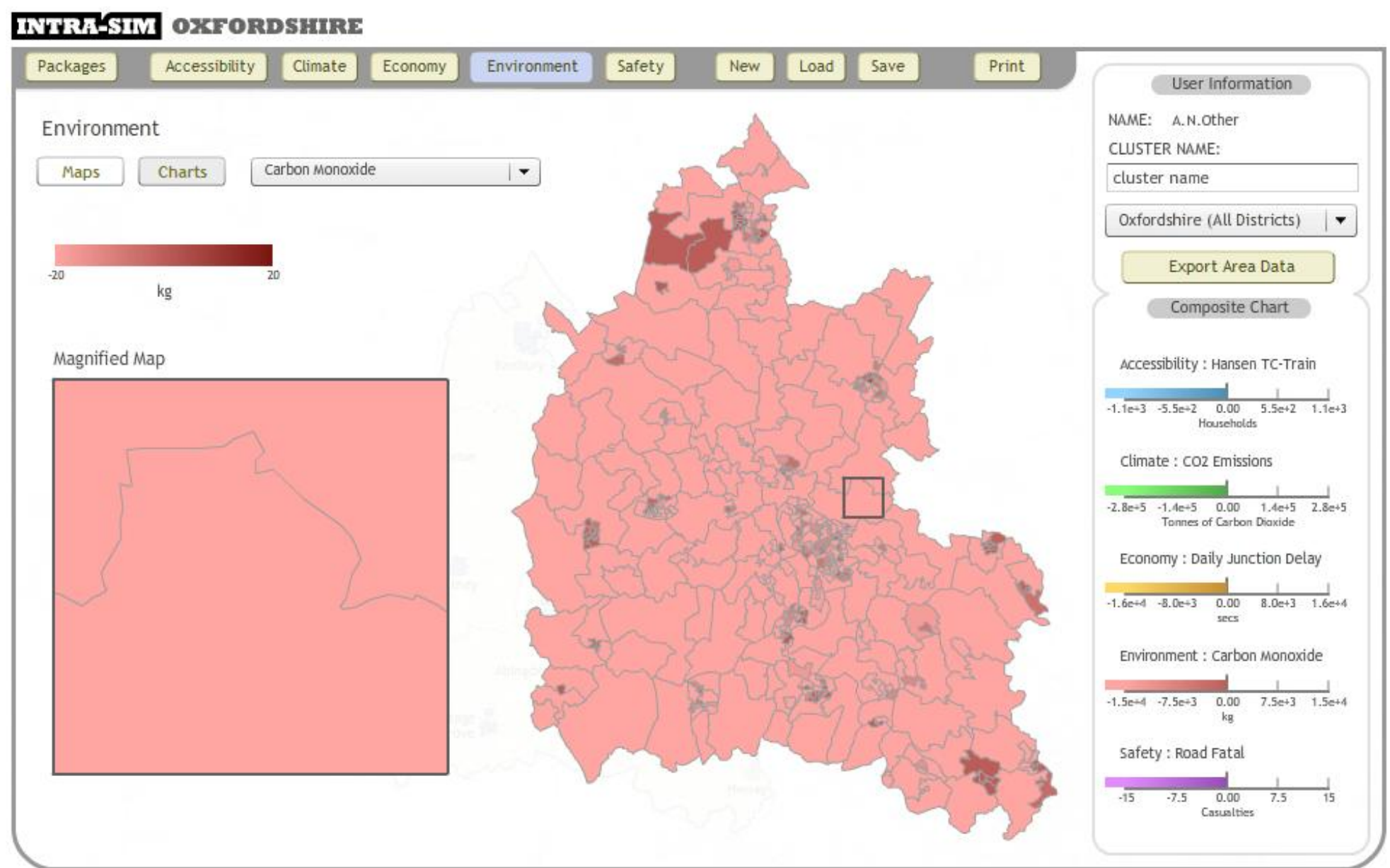


Figure 9: Scenario 2 'Sustainable Mobility' - Safety (Road Fatals)

INTRRSSIM OXFORDSHRE

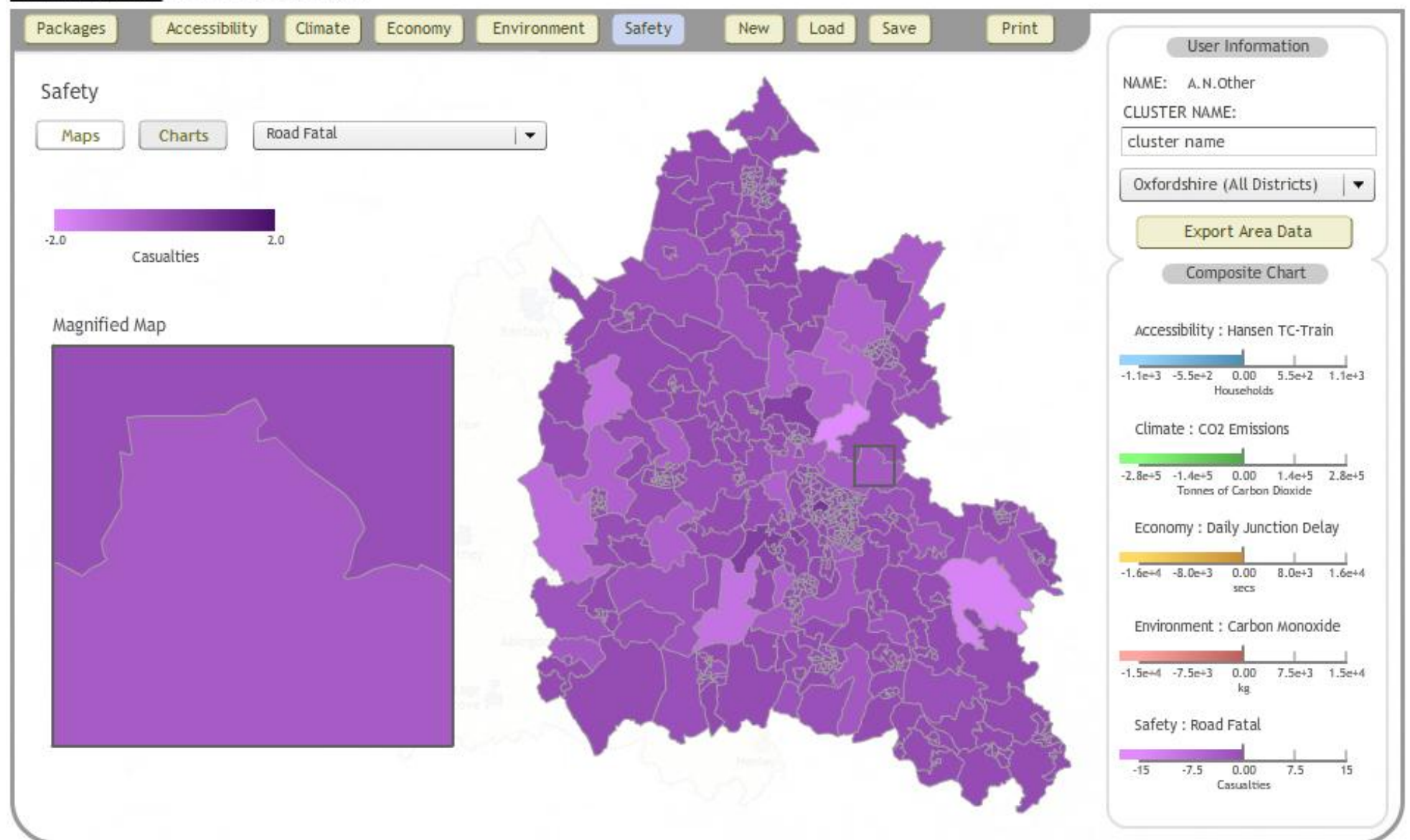

